\title{
The Sting Jet in a Simulated Extratropical Cyclone
}

\author{
Zuohao Cao*
}

\author{
Meteorological Service of Canada, Environment Canada, Toronto, Ontario, Canada
}

\begin{abstract}
The sting jet (SJ), distinguished from warm and cold conveyor belt jets, has significant impacts on our society and economy through producing damaging surface winds. The purpose of this study is to confirm two scientific hypotheses on the SJ through diagnosing the idealized numerical simulation. It is confirmed that the SJ exists and produces severe surface winds in the simulated extratropical cyclone with explosively deepening and formation of the bent-back front. It is shown that strong winds in the SJ with a speed of about $30 \mathrm{~m} \mathrm{~s}^{-1}$ are first appeared in a cloud free zone. It is further demonstrated that the SJs are located at the tip of the bent-back front and the cloud head, and to the south/southwest of the surface low center. These features are in good agreement with observations. It is also confirmed that conditional symmetric instability (CSI) exists and is associated with the strengthening of the SJs at and after the mature stage of the simulated extratropical cyclone.
\end{abstract}

\section{INTRODUCTION}

The sting jet (SJ) is a mesoscale jet distinct from warm and cold conveyor belt jets. The SJ is characterized by severe surface winds that have significant impacts on our society and economy. For example, severe wind storms in Europe produced an insured losses of 24 billion euros since 1985 [1]. Severe surface winds are difficult to detect and predict. To improve their predictabilty, it is required to incorporate more intense observations and better physical processes into numerical weather prediction models through better understanding relevant physical mechanisms and features for development and maintenance of severe surface winds.

A few studies have been conducted to examine these features and/or physical processes. [1] revisited the Great Storm in October 1987 over south-east England, and he found that the most damaging surface winds in extratropical cyclones are associated with a bent-back front and cloud head. Based on observational analyses, [1] hypothesized that the mesoscale circulations associated with conditional symmetric instability (CSI) and atmospheric evaporation may play an active role in strengthening the damaging winds. However, several key issues still remain to be resolved, for example, (1) if SJ exists and plays a similar role in other damaging extratroipcal cyclones, and the conceptual model presented in [1] is representative of most storms that deepen explosively and/or undergo frontal fracture; (2) if CSI exists and plays a role in the development of the SJ.

The objective of the present study is therefore to address the above-mentioned scientific questions. To resolve the first issue, the model outputs obtained from idealized numerical simulations have been diagnosed to confirm (a) if the simulated extratropical cyclone experiences an explosively deepening stage, and evolves a life-cycle model of [2], which includes frontal fracture, bent-back front, and warm-core

*Address correspondence to this author at the Meteorological Service of Canada, 4905 Dufferin Street, Toronto, Ontario, M3H 5T4, Canada; Tel: 416-739-4551; Fax: 416-739-4721; E-mail: zuohao.cao@ec.gc.ca frontal seclusion; (b) if there exist SJs in the idealized extratropical cyclone so that the previous findings on the SJs from the case study can be generalized.

CSI has been extensively investigated since it was first proposed as a possible mechanism for the formation of frontal rainbands by [3-5]. CSI may occur in regions where moist geostrophic potential vorticity, $\mathrm{MPV}_{\mathrm{g}}$, defined as

$\operatorname{MPV}_{\mathrm{g}}=\frac{1}{\rho}\left(\vec{\zeta}_{\mathrm{g}} \cdot \nabla \theta_{e}\right)$,

where $\vec{\zeta}_{\mathrm{g}}, \theta_{e}$, and $\rho$ are the geostrophic absolute vorticity vector, equivalent potential temperature, and density, respectively, becomes negative given that pure convective instability and inertial instability are excluded. [6] showed that the condition for CSI was satisfied in several cases of observed extratropical cyclones. With the aid of numerical simulations. [7] revealed substantial amounts of available potential energy for CSI prior to explosive cyclone development. It is therefore interesting to examine if the CSI exists and it plays an important role in the SJ development in extratropical cyclones, although other processes may also have some effects on the SJ evolution and structure.

In section 2 , the model description and initial conditions used in the simulation are presented. Diagnostic results obtained from the numerical modeling are given in sections 3,4 , and 5. Conclusions are made in section 6 .

\section{MODEL DESCRIPTION AND INITIAL CONDITION}

The Penn State University-National Center for Atmospheric Research (PSU-NCAR) three-dimensional mesoscale model [8] is used to simulate extratropical cyclones. This model has been modified by [9] to make it suitable for simulating baroclinic channeled flows with periodic boundary conditions at the east and west boundaries, and rigid-wall boundary conditions at the north and south boundaries. The horizontal domain size is 4000 $\mathrm{km}$ in the east-west (x) direction and $8000 \mathrm{~km}$ in the north- 
south (y) direction with horizontal grid spacing of $50 \mathrm{~km}$. The vertical $\sigma$-coordinate is used:

$\sigma=\frac{\mathrm{p}-\mathrm{p}_{\mathrm{t}}}{\mathrm{p}_{\mathrm{s}}-\mathrm{p}_{\mathrm{t}}}$

where $p_{t}(=300 \mathrm{hPa})$ and $p_{s}$ are the top and the surface pressure of the model, respectively. The model consists of 14 computational layers at $\sigma=0.996,0.986,0.960,0.920$, $0.870,0.805,0.730,0.645,0.550,0.450,0.350,0.250,0.150$ and 0.050 . The physical processes included in the model are explicit calculations of cloud water and rain water as timedependent variables [10], and the virtual temperature and water loading effects. The boundary layer process, usually resulting in reducing surface wind speed, is not included since we are interested in how strong surface wind speed can be simulated in an idealized simulation. Actually, the idealized numerical simulation without the boundary layer process provides us an opportunity to examine potential maximum surface wind speed, although it may not be corresponding to a special event. On the other hand, the simulation without the boundary layer process may inform us how strong surface wind speed can be over smooth underlying surfaces. The reader is referred to [9] for detailed descriptions of the model features used in this study.

As displayed in Fig. (1), the initial surface conditions show a perturbation with moderate amplitude representing the early phase of the extratropical cyclogenesis. Most of the surface meridional temperature gradients are localized in a $1250 \mathrm{~km}$ baroclinic zone (Fig. 1a). The specific humidity field varies from 1 to $10 \mathrm{~g} \mathrm{~kg}^{-1}$ (Fig. 1c), and the initial moisture gradients are more or less parallel to the potential temperature gradients (cf Figs. 1a, c). The initial moist potential vorticity is positive everywhere in the domain (Fig. 1d) and thus the model atmosphere is conditionally symmetric stable. Interested readers are referred to [9] for details.

\section{LIFE CYCLE OF THE SIMULATED EXTRATRO- PICAL CYCLONE}

Fig. (2) shows the evolution and the structure of the surface temperature field at different stages of the cyclone development. By 30 hours, the frontal fracture has formed (Fig. 2a). At 48 hours, a bent-back front and a T-bone structure $[2,11]$ have developed (Fig. 2b). The warm core enclosed by the $0^{\circ} \mathrm{C}$ isotherm is completely cut off at 66 hours (Fig. 2c) and then split into two parts at 72 hours (Fig. 2d). Overall, the simulated surface temperature field shows many features of the extratropical cyclogenesis, such as the frontal fracture, the bent-back front and the T-bone structure, and the seclusion of the warm core enclosed by the $0^{\circ} \mathrm{C}$ isotherm. The life cycle of the simulated extratropical cyclone is similar to that of [2], and agrees very well with observational studies by [12,13].

The simulated cyclone experiences significant changes in surface pressure at the cyclone center. The simulated cyclone explosively deepens from 1006 to $945 \mathrm{hPa}$ (Fig. 3c) in the first $48 \mathrm{~h}$, at an average rate of $1.27 \mathrm{hPa} \mathrm{h}^{-1}$.

\section{EVIDENCE OF THE STING JET}

Different from warm and cold conveyor belt jets that are well-known features in extratropical cyclones, the SJ has been recently documented in the literature only through one observational event [1]. To our knowledge, the SJ phenomenon is examined through the idealized numerical simulations for the first time. Since the SJ produces damaging surface winds during the short period of time and its physical mechanism is not well understood yet, the SJ phenomenon is received more attention recently.



Fig. (1). Horizontal distributions of the model initial conditions at the surface: (a) temperature at intervals of $4^{\circ} \mathrm{C}$, (b) pressure at intervals of $4 \mathrm{hPa}$, (c) specific humidity at intervals of $2 \mathrm{~g} \mathrm{~kg}^{-1}$, (d) moist potential vorticity in the unit of 0.1 PVU. The abscissa is in the $\mathrm{X}$ direction and the ordinate is in the $\mathrm{Y}$ direction. Here $\mathrm{N} \uparrow$ denotes the north. The distance between two ticks is $100 \mathrm{~km}$.

The SJ is a type of low-level jets, and it is very often located at south and/or southwest of a cyclone center. Because a low-level jet is usually characterized with strong wind speed greater than $20 \mathrm{~m} \mathrm{~s}^{-1}$ [14] near $850-\mathrm{hPa}$ pressure surfaces [15], the model level close to $850-\mathrm{hPa}$ pressure and the surface level are received a particular attention. In this study, the region with the low-level wind speed greater than $25 \mathrm{~m} \mathrm{~s}^{-1}$ and its location to south and/or southwest of a 

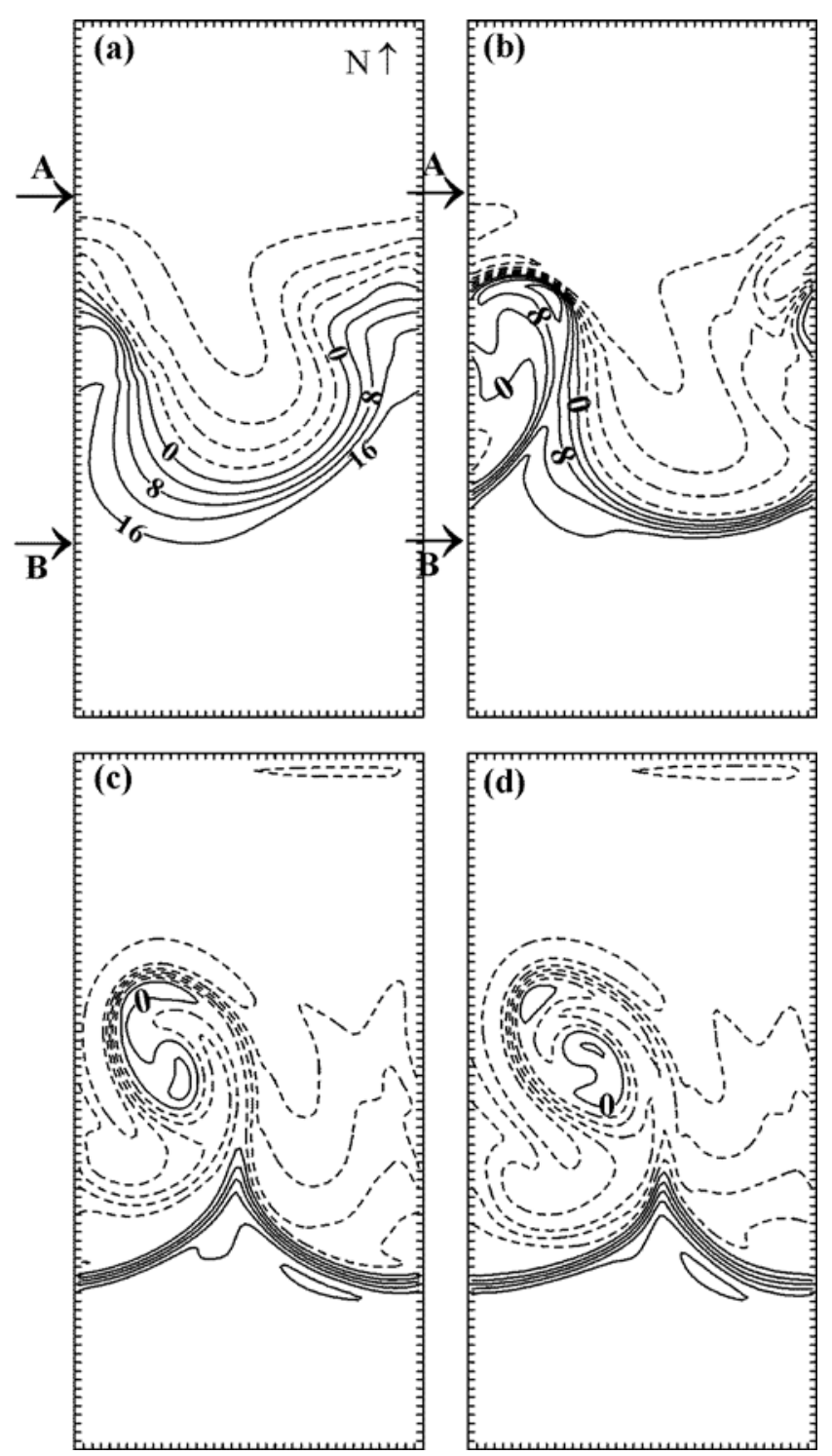

Fig. (2). Surface temperature field at hours (a) 30, (b) 48, (c) 66, and (d) 72 . The contour interval is $4^{\circ} \mathrm{C}$.

cyclone center is referred to as the SJ hereafter. Fig. (3) shows the surface pressure field and wind speed greater than $25 \mathrm{~m} \mathrm{~s}^{-1}$. As observed in Fig. (3a), at $30 \mathrm{~h}$ a high speed zone with the maximum surface wind speed of $31 \mathrm{~m} \mathrm{~s}^{-1}$ is developed at southwest of the cyclone center. This high speed zone is a SJ that distinguishes from the other jets to the east and northeast of the cyclone center. With further deepening of the cyclone (Fig. 3b), the maximum surface wind speed in the SJ reaches about $40 \mathrm{~m} \mathrm{~s}^{-1}$ at $42 \mathrm{~h}$ (Fig. 3b). Since the most damaging surface wind appears at the mature stage of extratropical cyclones characterized by a bent-back front or T-bone structure, we also pay close attention to surface winds at a time when the simulated cyclones evolve into the bent-back front. As shown in Fig. (2b), the simulated extratropical cyclone involves the formation of a bent-back front at $48 \mathrm{~h}$. At the same time, strong surface winds in the SJs are developed to the south and southwest of the surface low with the maximum wind speed about $54 \mathrm{~m} \mathrm{~s}^{-}$ ${ }^{1}$ at the surface (Fig. 3c).
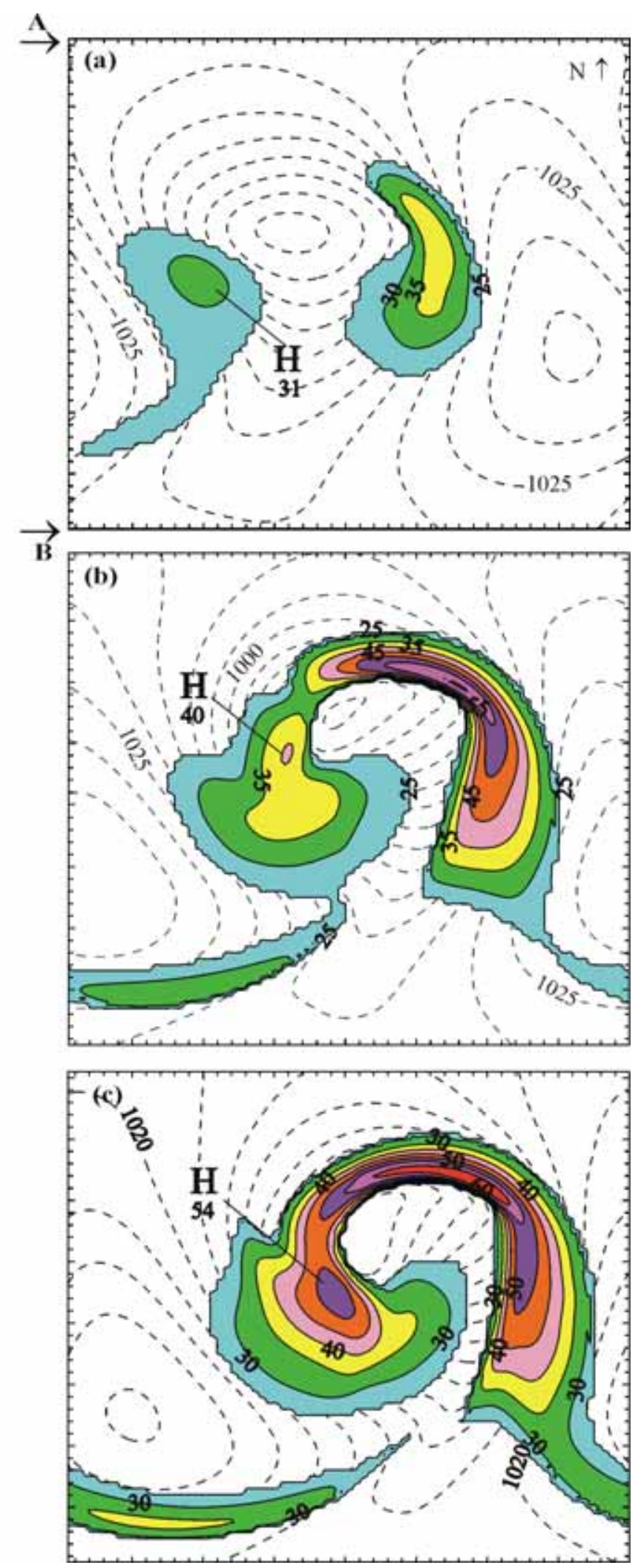

Fig. (3). Surface pressure field (dashed lines) at intervals of $5 \mathrm{hPa}$ and surface wind speed above $25 \mathrm{~m} \mathrm{~s}^{-1}$ at intervals of $5 \mathrm{~m} \mathrm{~s}^{-1}$ at (a) $30 \mathrm{~h}$, (b) $42 \mathrm{~h}$, and (c) $48 \mathrm{~h}$. Note that the north-south window size is indicated by the line $\mathrm{AB}$ in Fig. (2), and the features of interest are positioned at or near the center of simulation domain. Hs are defined as local maxima. 
Fig. (4) shows the 871-hPa level wind speed greater than $25 \mathrm{~m} \mathrm{~s}^{-1}$ and cloud fields. At the 871-hPa level, SJ features to the southwest of the cyclone have been observed (Fig. 4a). Comparisons between the wind speeds (Fig. 4a) and the cloud field (Fig. 4d) show that the SJ with the maximum
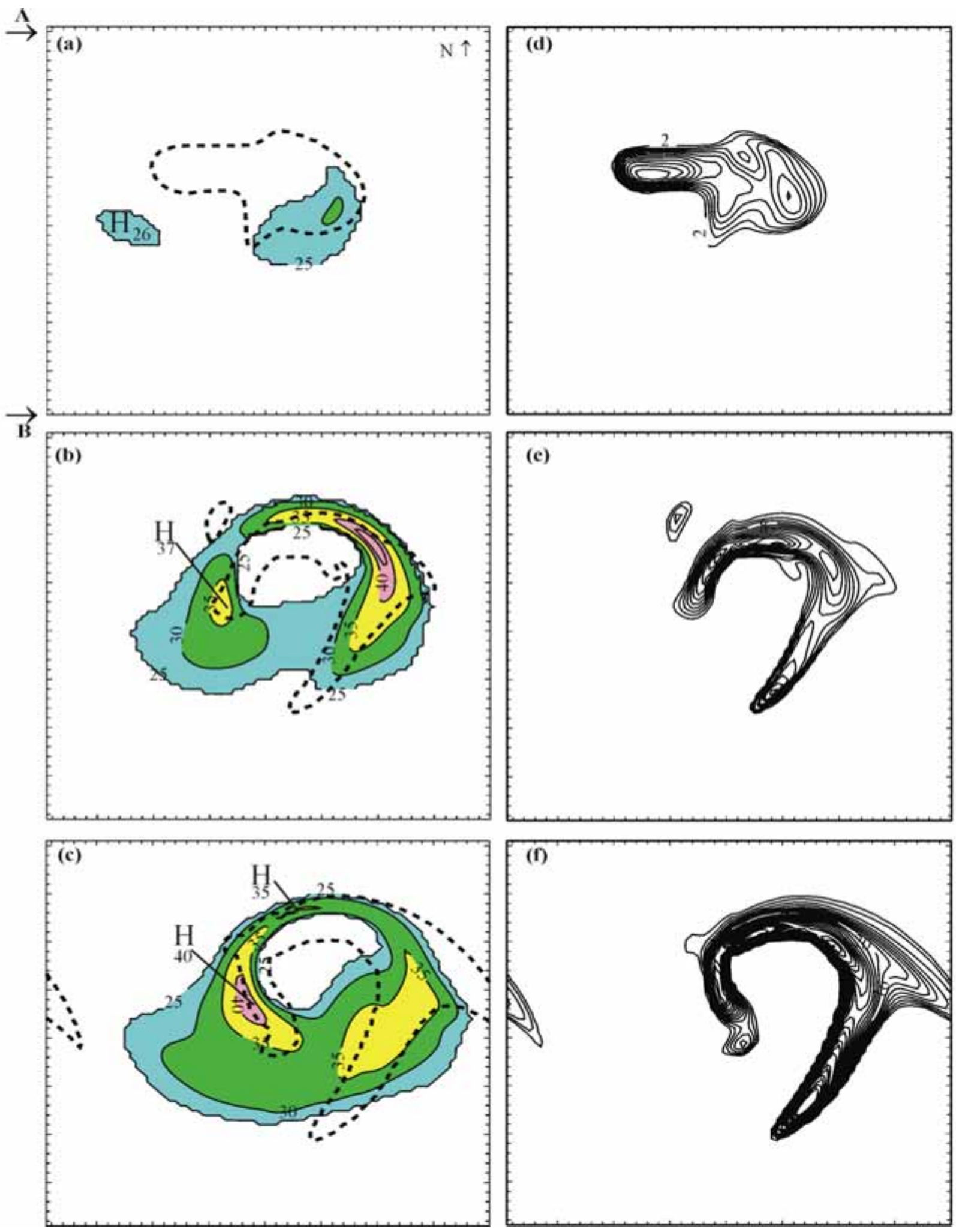

Fig. (4). Wind speed above $25 \mathrm{~m} \mathrm{~s}^{-1}$ at intervals of $5 \mathrm{~m} \mathrm{~s}^{-1}$ (a) at $30 \mathrm{~h}$ on the $871-\mathrm{hPa}$ pressure surface, (b) at $42 \mathrm{~h}$ on the 871 -hPa pressure surface, and (c) at $48 \mathrm{~h}$ on the $757-\mathrm{hPa}$ pressure surface. (d), (e), and (f) are the same as (a), (b), and (c) except cloud water content at intervals of $2 \times 10^{-5} \mathrm{~g} \mathrm{~kg}^{-1}$. The dashed lines in (a), (b), and (c) indicate the boundary of cloud fields.

wind speed of $26 \mathrm{~m} \mathrm{~s}^{-1}$ at $30 \mathrm{~h}$ first appears in a cloud-free zone of the simulated extratropical cyclone. At $42 \mathrm{~h}$, the $\mathrm{SJ}$ to the south and southwest of the cyclone has been observed at the 871-hPa level with a maximum wind speed of $37 \mathrm{~m} \mathrm{~s}^{-1}$ (Fig. 4b). It is observed through comparing Fig. (4b) with

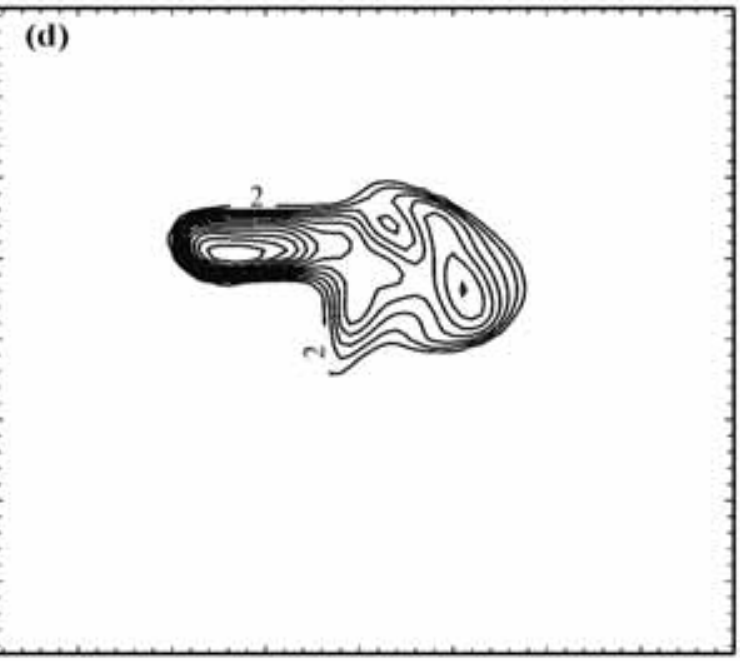

(e)

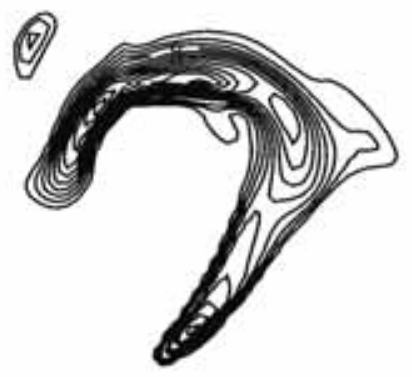


Fig. (4e) that at the mature stage, the 871-hPa high wind speed zones in the SJ are partially located in the cloud head. This agrees well with the observations [1]. At $48 \mathrm{~h}$, the strong winds in the SJs with the maximum wind speed of 40 $\mathrm{m} \mathrm{s}^{-1}$ are located at the tip of the bent-back front and at the cloud head (cf Figs. 4c, f). Since the SJ is usually originated from a region of strong descent around $750 \mathrm{hPa}$ pressure surface, we have also examined wind speed and its structure at this level. As shown in Fig. (4c), at the 757-hPa pressure surface there are three distinct strong wind zones (wind speed greater than $35 \mathrm{~m} \mathrm{~s}^{-1}$ ) such as the one to the east of the surface low center, the one to the north of the low center, and SJs to the southwest/south of the low center, respectively. These features are also in good agreement with the observations.

As demonstrated above, the SJs are originated in and at the edge of the cloud head or even in cloud-free regions, indicating that evaporation is associated with the SJ development. Based on the simulation performed in this study, there is a close spatial relationship between the region of most severe winds and the rapidly evaporating cloud-head tip, which was also identified through the observational study by [1]. Furthermore, [1] suggested that the evaporation is associated with slantwise circulations, induced by CSI, in the cloud head to enhance the strength of the surface winds. The role of CSI in the SJ development will be discussed in the next section.

\section{CSI AND THE STING JET}

Numerous studies have been documented in the literature on what resolution CSI can be resolved [16-18]. However, there is no any consensus available yet on this issue. For example, [16] showed that CSI can be resolved with a resolution of $40 \mathrm{~km}$ and it is absent at a resolution of $80 \mathrm{~km}$ in their 2-D numerical simulations. With about $60 \mathrm{~km}$ (on average) resolution observations, [17] identified that the observed regions of negative absolute vorticity are a response to CSI. Recently, [19] have identified CSI in several extratropical cyclones using the limited-area version of the Met Office's Unified Model with a resolution of close to $50 \mathrm{~km}$. Our model resolution of $50 \mathrm{~km}$ is also within the above range of 40 to $60 \mathrm{~km}$ for identifying the existence of CSI.

To identify the existence of CSI, the following criteria have been used in this study [19]:

$$
\left\{\begin{array}{l}
\mathrm{MPV}_{\mathrm{g}}<0 \\
\frac{\partial \theta_{\mathrm{e}}}{\partial \mathrm{p}}<0 \\
\frac{\partial \mathrm{v}_{\mathrm{g}}}{\partial \mathrm{x}}-\frac{\partial \mathrm{u}_{\mathrm{g}}}{\partial \mathrm{y}}+f>0 \\
\text { Relative humidity }(\mathrm{RH})>95 \% \\
\text { Vertical velocity }(\mathrm{w})>0
\end{array}\right.
$$

where $\mathrm{u}_{\mathrm{g}}$ and $\mathrm{v}_{\mathrm{g}}$ are $\mathrm{x}$ and $\mathrm{y}$ components of the geostrophic wind, and $\mathrm{f}$ is the Coriolis parameter. Since negative $\mathrm{MPV}_{\mathrm{g}}$ can be resulted from potentially symmetrical instability, or convective instability, or horizontal inertial instability, or combination of them, the second and third criteria are introduced to exclude convective and inertial instability. To release CSI, sufficient moisture and lift conditions need to be present [19]. The diagnostic (3) measures the full amount of vertically integrated extent of realizable CSI (hereafter referred to as VRC) over all levels whereas the slantwise convective available potential energy (SCAPE) highlights potential CSI for air originating at only one level. Furthermore, the diagnostic (3) is more efficient in terms of numerical computation than the SCAPE method [19].

The plots on the right-hand side of Fig. (5) show the VRC diagnostic. Similar to [19], the threshold for a significant region of CSI is 3 unstable levels. As displayed in Fig. (5d-f), at $30 \mathrm{~h}$ CSI becomes visible mainly along the baroclinic zone. Comparisons between Fig. $(\mathbf{5 a}, \mathbf{d})$ indicate that at $30 \mathrm{~h}$ CSI does not yet occur in the region where SJs exist. At $42 \mathrm{~h} \mathrm{CSI}$ is appeared in the cold front, the warm front, and the bent-back front (Fig. 5e). In particular, the CSI in the bent-back front region is located in the regions where both the SJ (Fig. 5b) and the cloud head (Fig. 4e) appear. This suggests that CSI plays an important role in the maintenance of SJs at the mature stage of the simulated extratropical cyclone. At $48 \mathrm{~h}$, with the existence of CSI (Fig. 5f) and the cloud head (Fig. 4f) in the SJs (Fig. 5c), the surface severe winds are further intensified. These findings have confirmed [1]'s observation based hypothesis that CSI exists and plays an active role in strengthening the damaging surface winds.

\section{CONCLUSIONS}

The SJ in an idealized extratropical cyclone has been investigated in this paper. In particular, two scientific issues have been addressed on (1) whether or not the SJs exist and produce severe surface winds in the extratropical cyclone that experiences explosively deepening stages and evolves into formation of bent-back fronts, and (2) whether or not CSI exists and plays an important role in development of the SJs in extratropical cyclones. These hypotheses have been tested with the aid of the idealized numerical simulations of the extratropical cyclone. The simulated cyclone undergoes the explosively deepening stage and develops into the bentback front or T-bone structure. It is shown that strong surface winds in the SJ with a speed of about $30 \mathrm{~m} \mathrm{~s}^{-1}$ first occur in a cloud free region of the extratropical cyclone. At the mature stage of the simulated cyclone, strong wind speed with a magnitude of about $40 \mathrm{~m} \mathrm{~s}^{-1}$ in the SJ is found in the cloud head. With the further evolution of the extratropical cyclone, the SJ with surface wind speed greater than $50 \mathrm{~m} \mathrm{~s}^{-1}$ is located at the tip of the bent-back front/the cloud head, and to the south/southwest of the surface cyclone center. The second scientific hypothesis is also confirmed through the idealized numerical simulation that CSI exists and plays an important role in the strengthening the SJs. The evaporation associated with CSI may also enhance the strength of the surface damaging winds. 

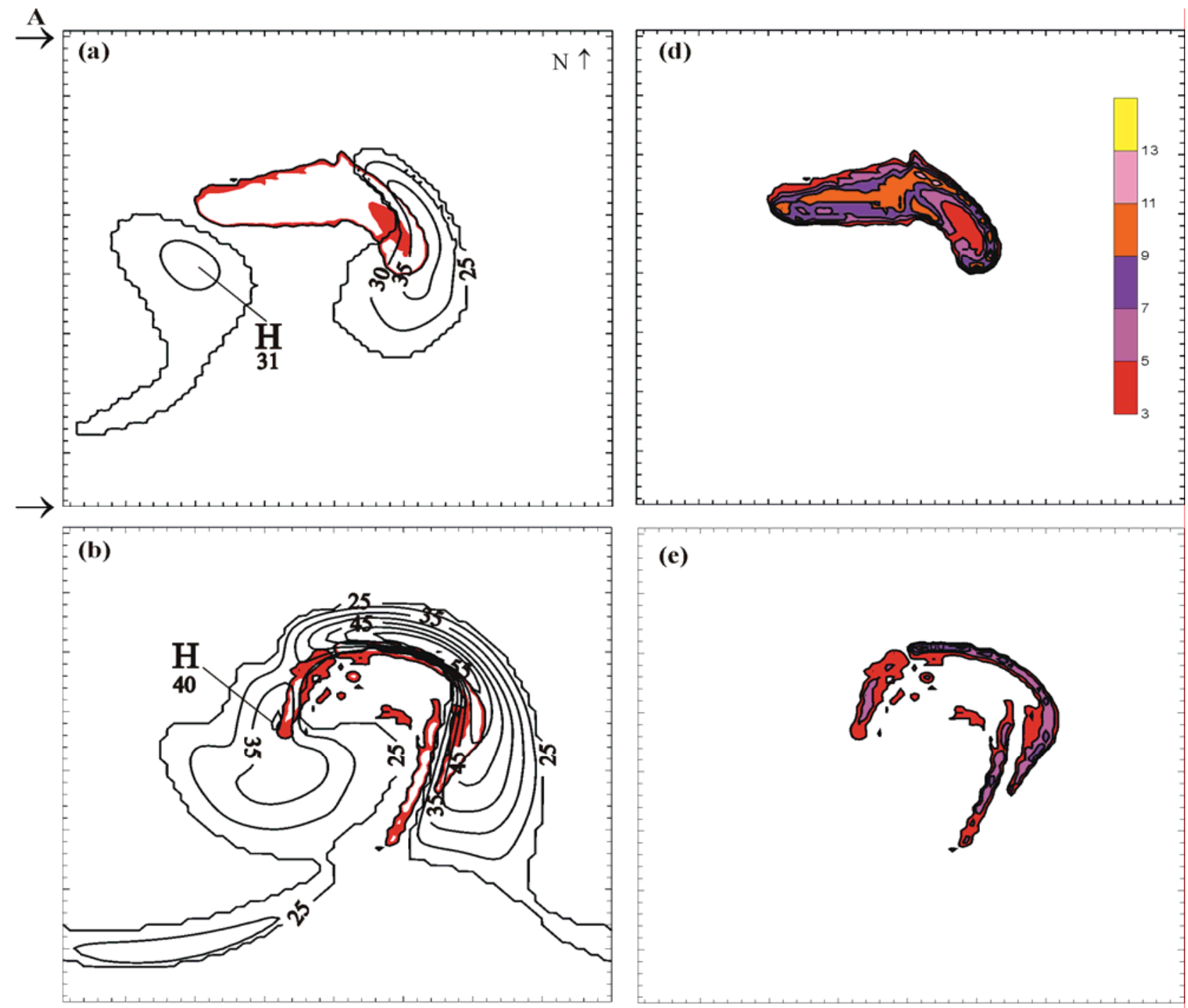

(e)
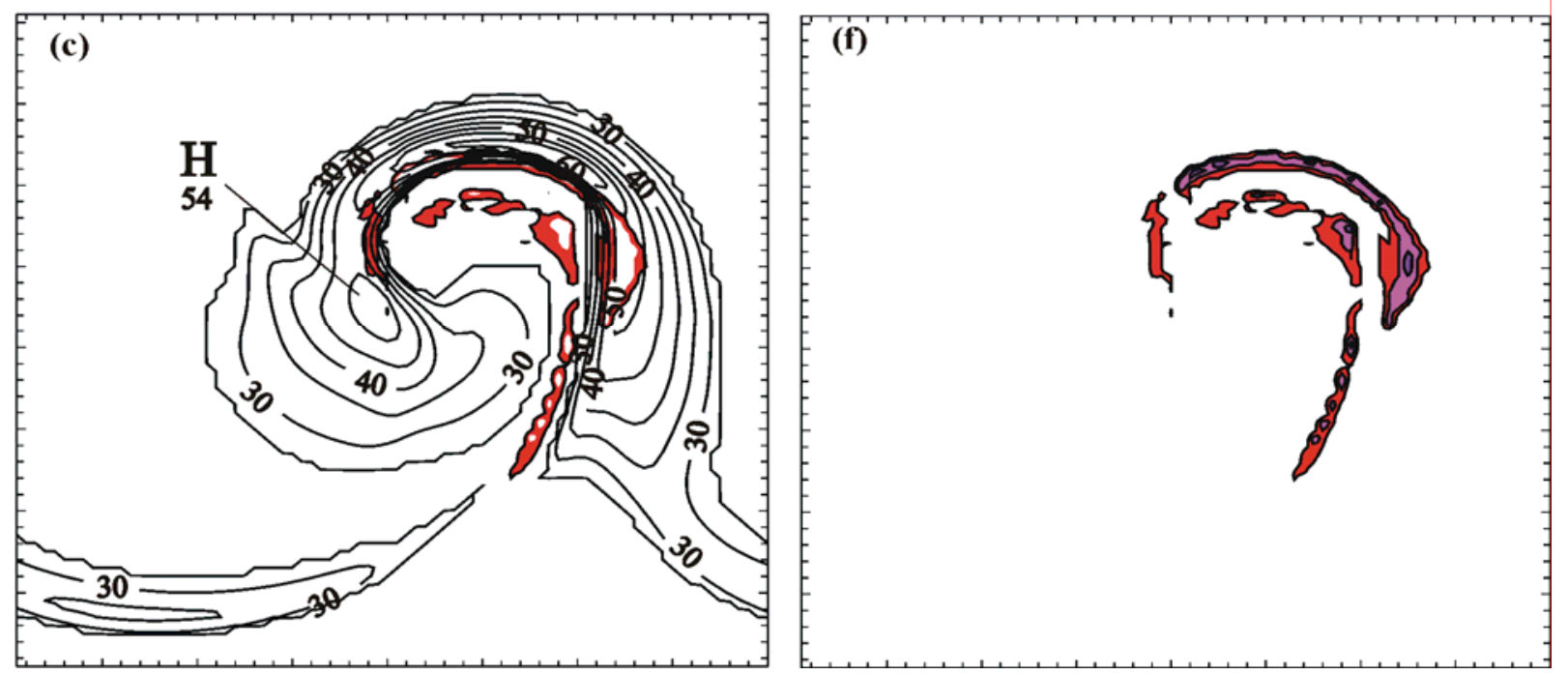

Fig. (5). Surface wind speed above $25 \mathrm{~m} \mathrm{~s}^{-1}$ at intervals of $5 \mathrm{~m} \mathrm{~s}^{-1}$ at (a) $30 \mathrm{~h}$, (b) $42 \mathrm{~h}$, and (c) $48 \mathrm{~h}$. (d), (e), and (f) are the same as (a), (b), and (c) except for VRC (number of layers). The red lines in (a), (b), and (c) indicate the boundary with VRC values at least 3. 


\section{REFERENCES}

[1] Browning KA. The sting at the end of tail: Damaging winds associated with extratropical cyclones. Q J R Meteoral Soc 2004; 130: 375-99.

[2] Shapiro MA, Keyser D. Fronts, jet streams, and the tropopause. Extratropical cyclones. The erik palmén memorial volume. In: Newton CW, Holopainen E, Eds. USA: American Meteorology Society 1990; pp. 161-91.

[3] Bennetts DA, Hoskins BJ. Conditional symmetric instability - a possible explanation for frontal rainbands. Q J R Meteorol Soc 1979; 105: 945-62.

[4] Emanuel KA. Inertial instability and mesoscale convective systems. Part I: linear theory of inertial instability in rotating viscous fluids. J Atmos Sci 1979; 36: 2425-449.

[5] Emanuel KA. The lagrangian parcel dynamics of moist symmetric instability. J Atmos Sci 1983; 40: 2368-76.

[6] Bennetts DA, Sharp JC. The relevance of conditional symmetric instability to the prediction of mesoscale frontal rainbands. Q J R Meteor Soc 1982; 108: 595-602.

[7] Shutts GJ. Dynamical aspects of the October storm, 1987: A study of a successful fine-mesh simulation. Q J R Meteor Soc 1990; 116: 1315-47.

[8] Anthes RA, Hsie EY, Kuo YH. Description of the Penn State / NCAR Mesoscale Model Version 4 (MM4). NCAR Technical Note, NCAR / TN.282, 1987; p. 66.

[9] Cao Z, Cho HR. Generation of moist potential vorticity in extratropical cyclones. J Atmos Sci 1995; 52: 3263-81.

[10] Hsie EY, Anthes RA, Keyser D. Numerical simulation of frontogenesis in a moist atmosphere. J Atmos Sci 1984; 41: 258194.
[11] Kuo YH, Shapiro MA, Donall EG. The interaction between baroclinic and diabatic processes in a numerical simulation of a rapidly intensifying extratropical marine cyclone. Mon Wea Rev 1991; 119: 368-84.

[12] Neiman PJ, Shapiro MA. The life cycle of an extratropical marine cyclone. Part I: Frontal-cyclone evolution and thermodynamic airsea interaction. Mon Wea Rev 1993; 121: 2153-76.

[13] Neiman PJ, Shapiro MA, Fedor LS. The life cycle of an extratropical marine cyclone. Part II: Mesoscale structure and diagnostics. Mon Wea Rev 1993; 121: 2177-99.

[14] Helfand HM, Schubert SD. Climatology of the simulated Great Plains low-level jet and its contribution to the continental moisture budget of the United States. J Clim 1995; 8: 784-806.

[15] Blackadar AK. Boundary layer wind maxima and their significance for the growth of nocturnal inversions. Bull Am Meteorol Soc 1957; 38: 283-90.

[16] Knight DJ, Hobbs PV. The mesoscale and microscale structure and organization of clouds and precipitation in mid-latitude cyclones. Part XV: A numerical modeling study of frontogenesis and coldfrontal rainbands. J Atmos Sci 1988; 45: 915-30.

[17] Thorpe AJ, Clough SA. Mesoscale dynamics of cold fronts: Structures described by dropsoundings in FRONTS 87. Q J Roy Meteorol Soc 1991; 117: 903-41.

[18] Persson POG, Warner TT. Model generation of spurious gravity waves due to inconsistency of the vertical and horizontal resolution. Mon Wea Rev 1991; 119: 917-35.

[19] Dixon RS, Browning KA, Shutts GJ. The relation of moist symmetric instability and upper-level potential-vorticity anomalies to the observed evolution of cloud heads. Q J R Meteorol Soc 2002; 128: 839-59.

(C) Zuohao Cao; Licensee Bentham Open

This is an open access article licensed under the terms of the Creative Commons Attribution Non-Commercial License (http://creativecommons.org/licenses/by$\mathrm{nc} / 3.0 /$ ) which permits unrestricted, non-commercial use, distribution and reproduction in any medium, provided the work is properly cited. 